\title{
NeoAPACHE Study Protocol li. Relationship Between Radiographic Pulmonary Area and Pulmonary Hypertension, Mortality, and Hernia Recurrence in Newborns With CDH.
}

\section{llaria Amodeo}

Fondazione IRCCS Ca' Granda Ospedale Maggiore Policlinico, NICU, Milan

Nicola Pesenti

University of Milano-Bicocca, Department of Statistics and Quantitative Methods, Division of Biostatistics, Epidemiology and Public Health, Milan

\section{Genny Raffaeli}

Università degli Studi di Milano, Department of Clinical Sciences and Community Health, Milan

\section{Francesco Macchini}

Fondazione IRCCS Ca' Granda Ospedale Maggiore Policlinico, Department of Pediatric Surgery, Milan

\section{Valentina Condò}

Fondazione IRCCS Ca' Granda Ospedale Maggiore Policlinico, NICU, Milan

\section{Irene Borzani}

Fondazione IRCCS Ca' Granda Ospedale Maggiore Policlinico, Pediatric Radiology Unit, Milan,

\section{Nicola Persico}

Fondazione IRCCS Ca' Granda, Ospedale Maggiore Policlinico, Department of Obstetrics and Gynecology, Milan

\section{Isabella Fabietti}

Fondazione IRCCS Ca' Granda, Ospedale Maggiore Policlinico, Department of Obstetrics and Gynecology, Milan

\section{Giulia Bischetti}

Fondazione IRCCS Ca' Granda Ospedale Maggiore Policlinico, NICU, Milan

Anna Maria Colli

Fondazione IRCCS Ca' Granda Ospedale Maggiore Policlinico, Cardiology Department, Milan

\section{Stefano Ghirardello}

Fondazione IRCCS Ca' Granda Ospedale Maggiore Policlinico, NICU, Milan

\section{Silvana Gangi}

Fondazione IRCCS Ca' Granda Ospedale Maggiore Policlinico, NICU, Milan

\section{Mariarosa Colnaghi}

Fondazione IRCCS Ca' Granda Ospedale Maggiore Policlinico, NICU, Milan

\section{Fabio Mosca}


Fondazione IRCCS Ca' Granda Ospedale Maggiore Policlinico, NICU, Milan

Giacomo Cavallaro ( $\square$ giacomo.cavallaro@policlinico.mi.it)

Fondazione IRCCS Ca' Granda Ospedale Maggiore Policlinico, NICU, Milan

\section{Research Article}

Keywords: Congenital diaphragmatic hernia, radiographic lung area, lung hypoplasia, pulmonary hypertension, mortality, recurrence of the hernia, FETO.

Posted Date: January 4th, 2021

DOl: https://doi.org/10.21203/rs.3.rs-130719/v1

License: (a) This work is licensed under a Creative Commons Attribution 4.0 International License. Read Full License 


\section{Abstract}

To investigate the relationship between radiographic lung area and systolic pulmonary artery pressure (SPAP) on the first day of life, mortality, and hernia recurrence during the first year of life in infants with a congenital diaphragmatic hernia $(\mathrm{CDH})$.

Retrospective cohort study on $77 \mathrm{CDH}$ newborns. Lung area was calculated by tracing the lung's perimeter, excluding mediastinal structures and herniated organs, on the preoperative chest X-ray performed within 24 hours after birth. Echocardiographic SPAP value, deaths, and recurrence cases were recorded. Logistic and linear regression analyses were performed.

Deceased infants showed lower areas and higher SPAP values. One $\mathrm{cm}^{2}$ of rising in the total, ipsilateral, and contralateral area was associated with a $22 \%, 43 \%$, and $24 \%$ reduction in mortality risk. SPAP values showed a decreasing trend at birth, with a maximum of $1.84 \mathrm{mmHg}$ reduction per unitary increment in the ipsilateral area. Recurrence patients showed lower areas, with recurrence risk decreasing by $14 \%$ and $29 \%$ per unit increment of the total and ipsilateral area.

In $\mathrm{CDH}$ patients, lung area at birth reflects impaired lung development and defect size, being associated with increased SPAP values, mortality, and recurrence risk.

Clinical Trial Registration: The trial was registered at ClinicalTrials.gov with identifier NCT04396028.

\section{Introduction}

Congenital Diaphragmatic Hernia (CDH) is a severe congenital malformation with a wide outcome variability ${ }^{1}$. Pulmonary hypoplasia and persistent pulmonary hypertension $(\mathrm{PH})$ represent the two main determinants of patients' outcome, with still high mortality and morbidity ${ }^{2-10}$. The radiographic assessment of the lung area has been proposed as an alternative method to evaluate pulmonary hypoplasia soon after birth ${ }^{11-13}$. In newborns with $\mathrm{CDH}$, lung area is correlated to the functional residual capacity measured through the diluted helium technique, and its increase is associated with tidal volume improvement in the first year of life ${ }^{14,15}$. The chest radiographic thoracic area (CRTA) was also lower in patients with poor prognosis and was found to predict survival to discharge from the Neonatal Intensive Care Unit (NICU) better than lung to head ratio $(\mathrm{LHR})^{16}$. However, a possible association between lung area and pulmonary hypertension in defining patients' mortality has never been investigated.

Hernia recurrence represents one of the most common complications, and a sizeable diaphragmatic defect is one of the main independent risk factors ${ }^{17-23}$. The recurrence could occur weeks, months, or even years after the primary surgery, and patients often remain asymptomatic for a long time until complications arise. Therefore, the overall risk of recurrence during the life span remains unknown ${ }^{8}$. To our knowledge, an association between lung area and hernia recurrence has never been reported so far. 
Since lung hypoplasia and vascular development are strictly related, our hypothesis was that lower lung areas at birth could determine higher mortality and higher pulmonary pressure ${ }^{23-25}$. Moreover, provided that poor lung development comes with low lung area at birth, we supposed that lung area could indirectly reflect diaphragmatic defect size and be therefore associated with hernia recurrence $e^{14,16}$.

\section{Results}

The radiographic pulmonary area was assessed on 77 patients, 49 of whom survived to discharge and were alive at the age of one year (36.4\% mortality rate) (Fig. 1). The majority of CDH were left-sided, with a high prevalence of severe forms and liver herniation. Fetal endoscopic tracheal occlusion (FETO) was performed in one-third of the cases, while extracorporeal membrane oxygenation (ECMO) was required in three patients. In more than half of cases, a diaphragmatic patch was needed for surgical repair, and in one patient, an abdominal patch was also used (Table 1). 
Table 1

Characteristics of the study population.

\section{$\mathrm{CDH}(\mathrm{n}=77)$}

\section{Prenatal Data}

Side of defect - $\mathrm{n}(\%)$

$61(79.2)$

- Left CDH

- Right CDH

- Bilateral CDH

O/E LHR\% - mean (SD)

$35.3(12.7)$

- Initial

$49.4(15.7)$

- Final

Liver Up - $\mathrm{n}(\%)$

$51(66.2)$

Grading $\mathrm{CDH}-\mathrm{n}(\%)$

$32(41.6)$

- Severe

$13(16.9)$

- Moderate

$32(41.6)$

- Mild

FETO - n (\%)

$28(36.4)$

Postnatal Data

Gestational age (weeks) - mean (SD)

$36.6(2.2)$

Birth weight (g) - mean (SD)

$2744(586)$

Males - $\mathrm{n}(\%)$

$43(55.8)$

Inborn - $\mathrm{n}(\%)$

$74(96.1)$

Vaginal delivery - $\mathrm{n}(\%)$

40 (51.9)

APGAR $1^{\circ} \mathrm{min}$ - median (IQR)

$6(4-7)$

APGAR $5^{\circ} \mathrm{min}$ - median (IQR)

$8(7-9)$

Surgery $-\mathrm{n}(\%)$

66 (85.7)

Day of surgical repair - median (IQR)

$3(2-4)$

Diaphragmatic patch (on operated) - $\mathrm{n}(\%)$

$34(51.5)$

Abdominal patch (on operated) - $\mathrm{n}(\%)$

$1(1.5)$

Mechanical ventilation (days) - median (IQR)

$11(7-20.5)$ 


\begin{tabular}{|c|c|}
\hline \multicolumn{2}{|l|}{$\mathrm{CDH}(\mathrm{n}=77)$} \\
\hline ECMO - n (\%) & $3(3.9)$ \\
\hline Lenght of stay (days) - median (IQR) & $39(15-68)$ \\
\hline Deceased - n (\%) & $28(36.4)$ \\
\hline \multicolumn{2}{|l|}{ Radiographic Pulmonary Area } \\
\hline Total pulmonary area $\left(\mathrm{cm}^{2}\right)$ - mean (SD) & $12.6(7.0)$ \\
\hline Ipsilateral pulmonary area $\left(\mathrm{cm}^{2}\right)$ - mean (SD) & $3.9(3.5)$ \\
\hline Contralateral pulmonary area $\left(\mathrm{cm}^{2}\right)$ - mean (SD) & $8.6(4.3)$ \\
\hline
\end{tabular}

\section{Radiographic pulmonary area, pulmonary hypertension, and mortality.}

The study population was divided into two groups, deceased $(n=28)$ and survived $(n=49)$. Compared to survivors, deceased patients showed a lower mean observed/expected lung to head ratio (O/E-LHR\%) both at diagnosis and before birth, and the liver was herniated more frequently. Moreover, both gestational age and weight were lower, and patching insertion was significantly higher (Table 2). 
Table 2

Comparison between deceased and survived patients.

\begin{tabular}{|c|c|c|c|}
\hline & $\begin{array}{l}\text { DECEASED } \\
(\mathrm{n}=\mathbf{2 8})\end{array}$ & $\begin{array}{l}\text { SURVIVED } \\
(n=49)\end{array}$ & $p$-value \\
\hline \multicolumn{4}{|l|}{ Prenatal Data } \\
\hline Side of defect - n (\%) & $22(78.6)$ & $39(79.6)$ & $0.856^{\wedge}$ \\
\hline - Left CDH & $6(21.4)$ & $9(18.4)$ & \\
\hline - Right CDH & $0(0.0)$ & $1(2.0)$ & \\
\hline \multicolumn{4}{|l|}{ - Bilateral CDH } \\
\hline O/E LHR\% - mean (SD) & $28.4(7.6)$ & $40.1(13.4)$ & $<0.001 *$ \\
\hline - Initial & $42.1(13.5)$ & $54.2(15.3)$ & $0.001 *$ \\
\hline \multicolumn{4}{|l|}{ - Final } \\
\hline Liver up - n (\%) & $28(100)$ & $23(46.9)$ & $<0.001^{\wedge}$ \\
\hline Grading CDH - n (\%) & $19(67.9)$ & $13(26.5)$ & $<0.001^{\wedge}$ \\
\hline - Severe & $7(25.0)$ & $6(12.2)$ & \\
\hline - Moderate & $2(7.1)$ & $30(61.2)$ & \\
\hline \multicolumn{4}{|l|}{ - Mild } \\
\hline FETO - n (\%) & $16(57.1)$ & $12(24.5)$ & $0.006^{*}$ \\
\hline \multicolumn{4}{|l|}{ Postnatal Data } \\
\hline Gestational age (weeks) - mean (SD) & $35.6(2.4)$ & $37.2(1.9)$ & $0.002^{*}$ \\
\hline Birth weight (g) - mean (SD) & 2437 (438) & $2920(591)$ & $<0.001^{*}$ \\
\hline Males - n (\%) & $13(46.4)$ & $30(61.2)$ & $0.239^{\wedge}$ \\
\hline Vaginal delivery - n (\%) & $8(28.6)$ & $32(65.3)$ & $0.002^{\wedge}$ \\
\hline APGAR $1^{\circ} \mathrm{min}$ - median (IQR) & $4.5(3-6)$ & $6(5-8)$ & $0.003^{\circ}$ \\
\hline APGAR $5^{\circ}$ min - median (IQR) & $7(6-8)$ & $8(8-9)$ & $<0.001^{\circ}$ \\
\hline Surgery - n (\%) & $17(60.7)$ & $49(100)$ & $<0.001^{\wedge}$ \\
\hline Day of surgical repair - median (IQR) & $3(2-4)$ & $2(2-3.5)$ & $0.603^{\circ}$ \\
\hline Diaphragmatic patch (on operated) - n (\%) & $15(88.2)$ & $19(38.8)$ & $0.001^{\wedge}$ \\
\hline Abdominal patch (on operated) - $\mathrm{n}(\%)$ & $0(0.0)$ & $1(2.0)$ & $>0.999^{\wedge}$ \\
\hline Mechanical ventilation (days) - median (IQR) & $8(2-23.5)$ & $16(9-20)$ & $0.036^{\circ}$ \\
\hline
\end{tabular}




\begin{tabular}{|llll|}
\hline & $\begin{array}{l}\text { DECEASED } \\
(\mathbf{n = 2 8})\end{array}$ & $\begin{array}{l}\text { SURVIVED } \\
(\mathbf{n = 4 9 )}\end{array}$ & $p$-value \\
\hline Oxygen (days) - median (IQR) & $7.5(2-31)$ & $13(3-27)$ & $0.426^{\circ}$ \\
\hline Nitric Oxyde (days) - median (IQR) & $8(2-21)$ & $9(0-15)$ & $0.380^{\circ}$ \\
\hline Sildenafil (days) - median (IQR) & $7(2-29.5)$ & $0(0-31)$ & $0.077^{\circ}$ \\
\hline Lenght of stay (days) - median (IQR) & $8(2-31)$ & $44(35.5-70.5)$ & $<0.001^{\circ}$ \\
\hline
\end{tabular}

CDH: congenital diaphragmatic hernia; O/E LHR: observed/expected lung-to-head ratio; FETO: fetal endoscopic tracheal occlusion; n: number; IQR: interquartile range; SD: standard deviation; *: Student's T-Test; : Mann Whitney U Test; ${ }^{\wedge}$ : Fisher Exact Test.

At all times, deceased patients showed higher systolic pulmonary arterial pressure (SPAP) values compared to survivors (sPAP T0: $54.4 \pm 5.3 \mathrm{mmHg}$ vs $64.4 \pm 17.2 \mathrm{mmHg}, \mathrm{p}=0.016$; sPAP T1: $50.6 \pm$ $16.2 \mathrm{mmHg}$ vs $60.7 \pm 10.9 \mathrm{mmHg}, p=0.022$; SPAP T2: $46.4 \pm 17.7 \mathrm{mmHg}$ vs $55.1 \pm 17.9 \mathrm{mmHg}, \mathrm{p}=$ 0.163; sPAP T3: $38.8 \pm 13.6 \mathrm{mmHg}$ vs $65.7 \pm 16.5 \mathrm{mmHg}, \mathrm{p}<0.001$ ) (Fig. 2, Panel A). They also showed lower mean total, ipsilateral and contralateral pulmonary areas at birth (total pulmonary area: $15.1 \pm$ $6.9 \mathrm{~cm}^{2}$ vs $8.1 \pm 4.6 \mathrm{~cm}^{2}, \mathrm{p}<0.001$; ipsilateral pulmonary area: $5.1 \pm 3.4 \mathrm{~cm}^{2}$ vs $1.8 \pm 2.6 \mathrm{~cm}^{2}, \mathrm{p}<0.001$; contralateral pulmonary area, $10.0 \pm 4.3 \mathrm{~cm}^{2}$ vs $6.2 \pm 3.0 \mathrm{~cm}^{2}, \mathrm{p}<0.001$ ) (Fig. 2, Panel B).

At birth, pulmonary area and SPAP were significantly associated: as the three areas increased, SPAP at T0 significantly decreased, as shown by the linear regression model (Table 3, Panel A). 
Table 3

Radiographic lung area and outcome.

\begin{tabular}{|c|c|c|c|c|}
\hline \multirow[t]{5}{*}{ Panel A } & Radiographic Pulmonary Area & \multicolumn{3}{|c|}{ sPAP at T0 } \\
\hline & Area $\left(\mathrm{cm}^{2}\right)$ & B & $95 \% \mathrm{Cl}$ & p-value \\
\hline & Total & -0.85 & $-1.44,-0.25$ & 0.006 \\
\hline & Ispilateral & -1.84 & $-3.06,-0.62$ & 0.004 \\
\hline & Contralateral & -1.09 & $-2.08,-0.09$ & 0.032 \\
\hline \multirow[t]{5}{*}{ Panel B } & Radiographic Pulmonary Area & \multicolumn{3}{|c|}{ Death } \\
\hline & Area $\left(\mathrm{cm}^{2}\right)$ & OR & $95 \% \mathrm{Cl}$ & $p$-value \\
\hline & Total & 0.78 & $0.69,0.89$ & $<0.001$ \\
\hline & Ipsilateral & 0.57 & $0.43,0.76$ & $<0.001$ \\
\hline & Contralateral & 0.76 & $0.63,0.91$ & 0.003 \\
\hline \multirow[t]{3}{*}{ Panel C } & Pulmonary Hypertension & \multicolumn{3}{|c|}{ Death } \\
\hline & sPAP (mmHg) & OR & $95 \% \mathrm{Cl}$ & $\mathrm{p}$-value \\
\hline & T0 & 1.04 & $1.00,1.07$ & 0.034 \\
\hline \multirow[t]{5}{*}{ Panel D } & Radiographic Pulmonary Area & \multicolumn{3}{|c|}{ Hernia Recurrence } \\
\hline & Area $\left(\mathrm{cm}^{2}\right)$ & OR & $95 \% \mathrm{Cl}$ & $p$-value \\
\hline & Total & 0.86 & $0.75,1.00$ & 0.042 \\
\hline & Ipsilateral & 0.71 & $0.53,0.95$ & 0.022 \\
\hline & Contralateral & 0.86 & $0.71,1.05$ & 0.148 \\
\hline \multicolumn{5}{|c|}{$\begin{array}{l}\text { Panel A: linear regression analysis between radiographic pulmonary area and SPAP at T0, corrected } \\
\text { for gestational age. Panel B: logistic regression analysis between radiographic pulmonary area and } \\
\text { death, corrected for gestational age. Panel C: Iogistic regression analysis between sPAP at T0 and } \\
\text { death, corrected for gestational age. Panel D: logistic regression analysis between radiographic } \\
\text { pulmonary area and recurrence, corrected for gestational age. }\end{array}$} \\
\hline \multicolumn{5}{|c|}{ Results are corrected for gestational age. SPAP: Systolic Pulmonary Arterial Pressure. } \\
\hline
\end{tabular}

Following logistic regression analysis with death as the outcome variable, the increase in all radiographic parameters was also significantly related to improved survival in the first year of life (Table 3, Panel B).

Finally, with increasing SPAP at T0, the risk of death significantly increased as well (Table 3, Panel C).

The Receiver Operating Characteristic (ROC) curve analysis showed that the total pulmonary area had an area under the curve (AUC) of 0.808 , and a cut off of $10.87 \mathrm{~cm}^{2}$ predicted survival with $77.6 \%$ sensitivity and $75 \%$ specificity (Fig. 3, Panel A1). The ipsilateral pulmonary area had an AUC of 0.772 , and a cut off 
of $2.08 \mathrm{~cm}^{2}$ predicted survival with $81.6 \%$ sensitivity and $68 \%$ specificity (Fig. 3, Panel A2). The contralateral pulmonary area had an AUC of 0.775 , and a cut off of $7.3 \mathrm{~cm}^{2}$ predicted survival with $75 \%$ sensitivity and 68\% specificity (Fig. 3, Panel A3).

\section{Radiographic pulmonary area and hernia recurrence}

Survivors at the end of the first year of life were divided into two groups based on hernia recurrence: recurrence $(n=10)$ and non-recurrence $(n=39)$ (Table 4). 
Table 4

Comparison between recurrence and non-recurrence hernia patients.

\begin{tabular}{|c|c|c|c|}
\hline & $\begin{array}{l}\text { RECURRENCE } \\
(n=10)\end{array}$ & $\begin{array}{l}\text { Non-RECURRENCE } \\
(n=39)\end{array}$ & $p$-value \\
\hline \multicolumn{4}{|l|}{ Prenatal Data } \\
\hline Side of defect - $n(\%)$ & $8(80.0)$ & $31(79.5)$ & $>0.999^{\wedge}$ \\
\hline - Left CDH & $2(20.0)$ & $7(17.9)$ & \\
\hline - Right CDH & $0(0.0)$ & $1(2.6)$ & \\
\hline \multicolumn{4}{|l|}{ - Bilateral CDH } \\
\hline O/E LHR\% - mean (SD) & $34.6(8.2)$ & $42.1(14.4)$ & $0.132^{\star}$ \\
\hline - Initial & $44.4(14.6)$ & $56.9(14.6)$ & $0.029 *$ \\
\hline \multicolumn{4}{|l|}{ - Final } \\
\hline Liver UP - n (\%) & $5(50)$ & $18(46.2)$ & $>0.999^{\wedge}$ \\
\hline Grading CDH - n (\%) & $4(40.0)$ & $9(23.1)$ & $0.002^{\wedge}$ \\
\hline - Severe & $4(40.0)$ & $2(5.1)$ & \\
\hline - Moderate & $2(20.0)$ & $28(71.8)$ & \\
\hline \multicolumn{4}{|l|}{ - Mild } \\
\hline FETO - n (\%) & $3(30.0)$ & $9(23.1)$ & $0.690^{\wedge}$ \\
\hline \multicolumn{4}{|l|}{ Postnatal Data } \\
\hline Gestational age (weeks) - mean (SD) & $37.5(1.5)$ & $37.1(2.0)$ & $0.563^{*}$ \\
\hline Birthweight (g) - mean (SD) & $2808(412)$ & $2949(630)$ & $0.506^{*}$ \\
\hline Day of surgical repair - median (IQR) & $3(2.75-4.25)$ & $2(2-3)$ & $0.066^{\circ}$ \\
\hline Diaphragmatic patch - n (\%) & $6(60.0)$ & $13(33.3)$ & $0.156^{\wedge}$ \\
\hline Abdominal patch - n (\%) & $0(0.0)$ & $1(2.6)$ & $>0.999^{\wedge}$ \\
\hline Mechanical ventilation (days) - median (IQR) & $20.5(15.25-26)$ & $12(8-18)$ & $0.013^{\circ}$ \\
\hline Lenght of stay (days) - median (IQR) & $55(43-111.75)$ & $42(33-66)$ & $0.028^{\circ}$ \\
\hline
\end{tabular}

The recurrence group mainly included severe-moderate forms ( $80 \%$ vs. $28.2 \%$ ), while most non-recurrence patients were mild ( $20 \%$ vs. $71.8 \%$ ). Although the mean initial O/E-LHR\% was not significantly different, 
the mean final O/E-LHR\% was lower in the recurrence group ( $44.4 \%$ vs. $56.9 \%, p=0.029)$. Even though diaphragmatic patching was higher in the recurrence group, this difference was not significant. Recurrence patients required longer intensive care (Table 4).

The mean total and ipsilateral pulmonary area were significantly lower in the recurrence compared to non-recurrence group (total pulmonary area: $16.2 \pm 7.2 \mathrm{~cm}^{2}$ vs $11.0 \pm 3.2 \mathrm{~cm}^{2}, \mathrm{p}=0.034$; ipsilateral pulmonary area: $5.7 \pm 3.4 \mathrm{~cm}^{2}$ vs $2.7 \pm 2 \mathrm{~cm}^{2}, p=0.011$ ), while the mean contralateral area was not significantly different $\left(10.5 \pm 4.5 \mathrm{~cm}^{2}\right.$ vs $\left.8.3 \pm 3.3 \mathrm{~cm}^{2}, p=0.164\right)$ (Fig. 2, Panel C).

The logistic regression model showed that as the total and ipsilateral areas increased, $\mathrm{CDH}$ recurrence significantly decreased (Table 3, Panel D).

The ROC curve analysis showed that the total pulmonary area had an AUC of 0.759 , and a cut off of $13.07 \mathrm{~cm}^{2}$ predicted a one-year follow-up free of hernia recurrence with $71.8 \%$ sensitivity and $80 \%$ specificity (Fig. 3, Panel B1). The ipsilateral pulmonary area had an AUC of 0.790 , and a cut off of $3.75 \mathrm{~cm}^{2}$ had $74.4 \%$ sensitivity and $60 \%$ specificity (Fig. 3, Panel B2).

\section{Comparison between FETO and non-FETO patients}

We performed a comparison between patients undergoing prenatal treatment (FETO, $n=28)$ and those expectantly managed (non-FETO, $n=49$ ) (Table 5). FETO group was more severely affected, as showed by lower mean O/E-LHR\% at diagnosis and a higher liver herniation rate. However, the mean O/E-LHR\% before birth was not significantly different. 
Table 5

Comparison between FETO and non-FETO patients, before and after excluding mild cases of CDH.

\begin{tabular}{|c|c|c|c|c|c|}
\hline & $\begin{array}{l}\text { FETO } \\
(n=28)\end{array}$ & $\begin{array}{l}\text { Non- } \\
\text { FETO } \\
(n=49)\end{array}$ & $\begin{array}{l}\mathrm{p}- \\
\text { value }^{1}\end{array}$ & $\begin{array}{l}\text { Non-FETO, } \\
\text { excluded } \\
\text { mild } \\
(n=17)\end{array}$ & $\begin{array}{l}\text { p- } \\
\text { value }^{2}\end{array}$ \\
\hline \multicolumn{6}{|l|}{ Prenatal Data } \\
\hline $\begin{array}{l}\text { Side of defect - n (\%) } \\
\text { - Left CDH } \\
\text { - Right CDH } \\
\text { - Bilateral CDH }\end{array}$ & $\begin{array}{l}19(67.9) \\
8(28.6) \\
1(3.6)\end{array}$ & $\begin{array}{l}42 \\
(85.7) \\
7(14.3) \\
0(0.0)\end{array}$ & $0.094^{\wedge}$ & $\begin{array}{l}15(88.2) \\
2(11.8) \\
0(0.0)\end{array}$ & $0.341^{\wedge}$ \\
\hline Liver UP - n (\%) & $28(100)$ & $\begin{array}{l}23 \\
(46.9)\end{array}$ & $\stackrel{<}{0.001^{\wedge}}$ & $13(76.5)$ & $0.016^{\wedge}$ \\
\hline $\begin{array}{l}\text { O/E LHR\% - mean (SD) } \\
\text { - Initial } \\
\text { - Final }\end{array}$ & $\begin{array}{l}25.4(5.6) \\
51.8(15.4)\end{array}$ & $\begin{array}{l}42.7 \\
(11.3) \\
47.8 \\
(15.8)\end{array}$ & $\begin{array}{l}<.001 * \\
0.313^{*}\end{array}$ & $\begin{array}{l}35.1(7.9) \\
33.8(7.1)\end{array}$ & $\begin{array}{l}< \\
0.001 * \\
< \\
0.001 *\end{array}$ \\
\hline $\begin{array}{l}\text { Grading CDH - n (\%) } \\
\text { - Severe } \\
\text { - Moderate } \\
\text { - Mild }\end{array}$ & $\begin{array}{l}28(100) \\
0(0.0) \\
0(0.0)\end{array}$ & $\begin{array}{l}13 \\
(26.5) \\
32 \\
(65.3)\end{array}$ & $\dot{0} 001^{\wedge}$ & $\begin{array}{l}4(23.5) \\
13(76.5)\end{array}$ & $<001^{\wedge}$ \\
\hline \multicolumn{6}{|l|}{ Postnatal Data } \\
\hline Gestational age (weeks) - mean (SD) & $35(2.4)$ & $\begin{array}{l}37.5 \\
(1.5)\end{array}$ & $\stackrel{<}{<.001^{*}}$ & $37.1(1.7)$ & $0.003^{*}$ \\
\hline Birthweight (g) - mean (SD) & $2436(511)$ & $\begin{array}{l}2921 \\
(556)\end{array}$ & $<.001 *$ & $\begin{array}{l}2517 \\
(389)\end{array}$ & 0.576 * \\
\hline Surgery - n (\%) & $22(78.6)$ & $\begin{array}{l}44 \\
(89.8)\end{array}$ & $0.194^{\wedge}$ & $12(70.6)$ & $0.722^{\wedge}$ \\
\hline Day of surgical repair - median (IQR) & $2.5(2-3)$ & $3(2-4)$ & $0.603^{\circ}$ & $\begin{array}{l}3.5(2.25- \\
5)\end{array}$ & $0.040^{\circ}$ \\
\hline $\begin{array}{l}\text { Diaphragmatic patch (on operated) - } \mathrm{n} \\
(\%)\end{array}$ & $18(81.8)$ & $\begin{array}{l}16 \\
(36.4)\end{array}$ & $0.001^{\wedge}$ & $8(66.7)$ & $0.410^{\wedge}$ \\
\hline Abdominal patch (on operated) - $\mathrm{n}(\%)$ & $1(4.5)$ & $0(0.0)$ & $0.333^{\wedge}$ & $0(0.0)$ & ${ }^{>} .999^{\wedge}$ \\
\hline sPAP T0 (mmHg) - mean (SD) & $59.4(16.4)$ & $\begin{array}{l}58.2 \\
(17.1)\end{array}$ & $0.793^{*}$ & $\begin{array}{l}63.2 \\
(18.6)\end{array}$ & $0.513^{*}$ \\
\hline
\end{tabular}




\begin{tabular}{|c|c|c|c|c|c|}
\hline & $\begin{array}{l}\text { FETO } \\
(n=28)\end{array}$ & $\begin{array}{l}\text { Non- } \\
\text { FETO } \\
(n=49)\end{array}$ & $\begin{array}{l}\text { p- } \\
\text { value }^{1}\end{array}$ & $\begin{array}{l}\text { Non-FETO, } \\
\text { excluded } \\
\text { mild } \\
(n=17)\end{array}$ & $\begin{array}{l}\text { p- } \\
\text { value }^{2}\end{array}$ \\
\hline sPAP T1 (mmHg) - mean (SD) & $55.2(13.0)$ & $\begin{array}{l}53.7 \\
(16.5)\end{array}$ & $0.736^{\star}$ & $\begin{array}{l}63.1 \\
(13.6)\end{array}$ & $0.136 *$ \\
\hline sPAP T2 (mmHg) - mean (SD) & $48.3(15.2)$ & $\begin{array}{l}50.1 \\
(19.8)\end{array}$ & $0.767^{\star}$ & $\begin{array}{l}53.5 \\
(18.7)\end{array}$ & $0.459 *$ \\
\hline sPAP T3 (mmHg) - mean (SD) & $54.6(20.3)$ & $\begin{array}{l}42.1 \\
(17.1)\end{array}$ & $0.090^{*}$ & $\begin{array}{l}42.9 \\
(20.7)\end{array}$ & $0.228 *$ \\
\hline $\begin{array}{l}\text { Mechanical ventilation (days) - } \\
\text { median (IQR) }\end{array}$ & $16(9-25.5)$ & $\begin{array}{l}10(7- \\
18.5)\end{array}$ & $0.111^{\circ}$ & $15(5-23)$ & $0.582^{\circ}$ \\
\hline Oxygen (days) - median (IQR) & $\begin{array}{l}16(4.75- \\
34.75)\end{array}$ & $\begin{array}{l}8(2- \\
21.5)\end{array}$ & $0.145^{\circ}$ & $\begin{array}{l}13(2.5- \\
45)\end{array}$ & $0.761^{\circ}$ \\
\hline Nitric Oxyde (days) - median (IQR) & $11.5(6-22)$ & $\begin{array}{l}6(0- \\
14.5)\end{array}$ & $0.010^{\circ}$ & $9(2.5-17)$ & $0.337^{\circ}$ \\
\hline Sildenafil (days) - median (IQR) & $9(1-74.25)$ & $1(0-27)$ & $0.015^{\circ}$ & $6(0-38)$ & $0.334^{\circ}$ \\
\hline Lenght of stay (days) - median (IQR) & $41(9-94.5)$ & $\begin{array}{l}39(23- \\
51)\end{array}$ & $0.571^{\circ}$ & $\begin{array}{l}39(5- \\
80.5)\end{array}$ & $0.512^{\circ}$ \\
\hline Deceased - n (\%) & $16(57.1)$ & $\begin{array}{l}12 \\
(24.5)\end{array}$ & $0.006^{\wedge}$ & $10(58.8)$ & ${ }^{>} .999^{\wedge}$ \\
\hline Recurrence (on survivors) - n (\%) & $3(25.0)$ & $7(18.9)$ & $0.690^{\wedge}$ & $5(71.4)$ & $0.074^{\wedge}$ \\
\hline \multicolumn{6}{|l|}{ Radiographic Pulmonary Area } \\
\hline $\begin{array}{l}\text { Total pulmonary area }\left(\mathrm{cm}^{2}\right) \text { - mean } \\
\text { (SD) }\end{array}$ & $10.5(6.1)$ & $\begin{array}{l}13.7 \\
(7.3)\end{array}$ & $0.054^{\star}$ & $8.9(4.7)$ & $0.362^{*}$ \\
\hline $\begin{array}{l}\text { Ipsilateral pulmonary area }\left(\mathrm{cm}^{2}\right) \text { - } \\
\text { mean (SD) }\end{array}$ & $3.5(3.2)$ & $4.2(3.6)$ & $0.438^{*}$ & $1.3(2.0)$ & $0.015^{\star}$ \\
\hline $\begin{array}{l}\text { Contralateral pulmonary area }\left(\mathrm{cm}^{2}\right) \text { - } \\
\text { mean (SD) }\end{array}$ & $6.9(3.5)$ & $9.6(4.4)$ & $0.008^{*}$ & $7.6(3.8)$ & $0.523 *$ \\
\hline \multicolumn{6}{|c|}{$\begin{array}{l}\text { CDH: congenital diaphragmatic hernia; O/E LHR: observed/expected lung-to-head ratio; FETO: fetal } \\
\text { endoscopic tracheal occlusion; sPAP: Systolic Pulmonary Arterial Pressure; n: number; IQR: } \\
\text { interquartile range; SD: standard deviation; *: Student's T-Test; : Mann Whitney U Test; }{ }^{\wedge} \text { : Fisher Exact } \\
\text { Test.s }\end{array}$} \\
\hline
\end{tabular}

No substantial differences were found in the mean total and ipsilateral pulmonary area, while the mean contralateral pulmonary area was lower in the FETO group. 
Similarly, mean SPAP values were not significantly different, although FETO patients required more prolonged treatment with nitric oxide and sildenafil. Death occurred in $16(57.1 \%)$ FETO and $12(24.5 \%)$ non-FETO patients $(p=0.006)$. The recurrence rate among survivors was not significantly different between the two groups $(p=0.690)$. A prosthetic patch was used in $81.8 \%$ of FETO and $36.4 \%$ of nonFETO patients $(p<0.001)$ (Table 5).

Since mortality rate and need for pulmonary vasodilators were higher in the FETO group despite showing similar SPAP values and radiographic features, we performed a second comparison after excluding mild cases of $\mathrm{CDH}$, which were all allocated in the non-FETO group (Table 5$)^{2,26}$. The new population was constituted by 45 patients, divided into 28 FETO (100\% severe) and 17 non-FETO (76.5\% moderate and $23.5 \%$ severe).

Therefore, the previous differences largely disappeared. In addition, FETO had significantly lower initial but higher final O/E-LHR\% as compared to non-FETO. Finally, the mean total and contralateral pulmonary area were quite similar as well, while the ipsilateral area was significantly lower in the treated group (Table 5).

\section{Discussion}

We demonstrated an association between radiographic lung area, sPAP values, and death. Among survivors, lung area was also associated with hernia recurrence. As previously reported, our findings suggest a possible role of radiographic measurement as an easy, non-invasive, and reproducible tool in the early prediction of mortality and morbidity among $\mathrm{CDH}$ patients ${ }^{15}$.

Our results confirmed the invariable association between pulmonary hypoplasia, $\mathrm{PH}$, and death risk, as expected on a pathophysiological basis ${ }^{23,25,27}$.

In our cohort, lower O/E-LHR\% in the deceased group indicated a more fetal severe lung impairment, which was then reflected in smaller pulmonary areas at birth. Consequently, lung area and death were inversely related: one $\mathrm{cm}^{2}$ of rising in the ipsilateral area was associated with a $43 \%$ reduction in mortality, while variations in the total and contralateral area determined a reduction of $22 \%$ and $24 \%$, respectively.

Large-size defects have been previously associated with worse survival and pulmonary hypertension, suggesting that low lung volumes depict the link between these two elements ${ }^{6}$. Similarly, in our cohort, deceased infants were characterized by persistently higher SPAP values than survivors. In particular, sPAP values at birth showed a decreasing trend by $1.84 \mathrm{mmHg}$, with each $1 \mathrm{~cm}^{2}$ increase in the ipsilateral area.

Radiographic assessment and first SPAP measurement, both performed within 24 hours after birth, described the lung condition in a defining moment. Subsequently, several factors could influence pulmonary hypertension, such as pharmacological treatments, infections, patency of the ductus arteriosus, or surgery timing. The contribution of these factors could be neither captured nor predicted by 
the imaging performed at birth. For these reasons, it would be of interest to match lung area assessments and sPAP values at T1, T2, and T3, to clarify if this association is still confirmed over time and define possible trends.

Our findings were consistent with previous literature. A significantly lower CRTA was reported in newborns with $\mathrm{CDH}$ who died compared to survivors, and a CRTA greater than $12.99 \mathrm{~cm}^{2}$ was found to predict survival to discharge from NICU better than O/E-LHR\% at diagnosis, with $85 \%$ sensitivity and $73 \%$ specificity ${ }^{16}$. In our cohort, the best cut off and sensitivity were slightly lower. Even if specificity was higher, it still carried a wide margin of error in identifying patients at risk of death. Probably, the decision to consider only the aerated portions of the lungs led to an underestimation of lung surface, leading to low cut off values and discriminatory capacity.

Finally, after surgical repair, persistently elevated pulmonary pressure carried the highest risk of mortality, with a $16 \%$ increase in death risk for each sPAP unitary increment. Several studies have correlated the severity of $\mathrm{PH}$ with mortality. Dillon et al. evaluated mortality in a cohort of $\mathrm{CDH}$ patients and reported that all those with supra-systemic sPAP died ${ }^{25}$. Coughlin et al. reported that patients with higher PH at 1 month had a higher incidence of postoperative complications and worse survival, and persistently severe $\mathrm{PH}$ at 1 month was associated with increased mortality ${ }^{6}$. Similarly, looking at our results, we could assume that the most critical factor might not be the absolute value of SPAP or the presence of PH in the first hours after birth, rather its persistence over time ${ }^{6}$.

Small lung areas at birth result from poor lung development, but the interference of mechanical compression exerted by the herniated organs plays a considerable role. Therefore, after mechanical compression has been removed, the effective lung area's evaluation could greatly define lung hypoplasia and associated outcome. For example, Dimitriou et al. calculated the difference between the pre- and postoperative radiographic measurements, showing that postoperative improvement was higher in patients with a good outcome. They concluded that poor prognosis was correlated to low postoperative rather than low preoperative values, which was probably more related to mechanical compression than lung hypoplasia ${ }^{14}$. Therefore, the radiographic assessment of postoperative lung areas and the relative increase from preoperative values should be included in further analysis.

We demonstrated a significant association between preoperative radiographic measurements and hernia recurrence among survivors during the first year of life.

The overall recurrence rate of $20.4 \%$ in our cohort was in line with the literature reports ${ }^{17,22,28}$. In particular, the recurrence rate was higher in those patients with lower final O/E LHR\%, prolonged invasive respiratory support, and need for intensive care. Similarly, Al-lede et al. found a longer duration of mechanical ventilation and hospitalization in children with recurrence ${ }^{19}$. Notably, these patients showed a significantly lower mean total pulmonary area at birth than non-recurrence, mainly due to a significantly lower ipsilateral pulmonary area. 
As a consequence, we respectively observed a $14 \%$ and $29 \%$ reduction in recurrence risk in our cohort per unit increment of the total and ipsilateral area. Although it showed a lower trend in the recurrence group, the contralateral area did not seem to influence. The total radiographic area showed the best specificity in discriminating those patients at risk of recurrence, while the ipsilateral area showed better sensitivity.

Taken together, the lower ipsilateral area and O/E-LHR\% reflected the presence of a large diaphragmatic defect as the cause of poor lung development, indirectly confirming defect size as the leading risk factor for hernia recurrence ${ }^{17-20,22}$. In other words, we speculate that recurrence patients were somehow "predisposed" to this complication since birth and could have been identified early in the postnatal course.

The recurrence group's high patching rate suggested the presence of a wide defect, although this difference did not reach statistical significance. We cannot deduce any specific contribution of the patch in determining the recurrence risk due to the low sample size.

We observed that tracheal occlusion improved lung development and outcome through the descriptive comparison between FETO and non-FETO patients' characteristics.

Since prenatal treatment is reserved for severe cases of $\mathrm{CDH}$, the FETO group included only patients at one end of the spectrum of disease severity ${ }^{26}$. Nevertheless, final O/E-LHR\% before birth was even better in the FETO than in the untreated group, and the total and ipsilateral lung areas at birth did not significantly differ. Likewise, Dassios et al. observed that patients previously submitted to FETO procedure had a CRTA comparable to untreated patients with a similar mortality rate, reflecting a lung catch-up growth favored by the prenatal procedure ${ }^{16}$.

However, there was an inconsistency among higher mortality rates, similar SPAP values, and prolonged need for pulmonary vasodilators in the FETO group compared to the other. At first impression, we could argue that only a quantitative but not qualitative improvement in lung development was achieved with prenatal intervention since similar lung areas at birth seemed not to guarantee the same survival chances, apparently due to more severe pulmonary hypertension in FETO patients. However, after excluding mild cases, the two groups showed a similar outcome, suggesting that the initial findings were due to many mild cases in the untreated group. The final O/E LHR\% dramatically improved after the procedure, but the ipsilateral area was even significantly better in FETO than non-FETO patients.

In our cohort, the non-FETO group, which was primarily constituted by moderate cases, showed a $41.2 \%$ survival rate, in line with what is generally expected for this category of $\mathrm{CDH}^{2,29,30}$. As observed by Doneè et al., tracheal occlusion allowed improved outcomes in the operative group, similar to a moderate population expectantly managed ${ }^{31}$.

Finally, the recurrence risk was around $20 \%$ in both populations, despite higher patching in the FETO group, as previously observed by Ali et al. (41). Although it is the leading risk factor, the low recurrence rate suggests other factors besides the patch use as possible determinants of re-herniation ${ }^{18,32}$. Tsai et 
al. reported a non-significant difference in recurrence rate between patching and primary repair, despite a higher disease severity in the first group ${ }^{18}$. Jawaid et al. reported a low incidence of recurrence in patients in which Gore-Tex ${ }^{\circledR}$ patch was inserted ${ }^{32}$. Although we cannot conclude on the patch's contribution in determining the risk of re-herniation, we can observe that lower final O/E LHR\%, lower radiographic area at birth, and higher patching all suggest a common denominator influencing the risk of this complication $17,19,20,22$. Finally, we can speculate that lung catch-up growth in FETO patients conferred the same risk of recurrence as the untreated counterparts.

To the best of our knowledge, our study seems to be the first to evaluate the association between radiographic lung area and two important outcomes affecting newborns with $\mathrm{CDH}$ : pulmonary hypertension and hernia recurrence.

The radiographic measurement is easy, rapid, and can be performed soon after birth on the chest X-ray routinely performed at NICU admission. It would contribute to the early identification of infants at greater risk of developing higher SPAP values in the immediate postnatal period and at a higher likelihood of long-term hernia recurrence, as well as higher mortality, with a potential impact on patients' management. For example, the combined serial evaluation of lung area and SPAP over time could help to define trajectories related to the risk of persistently elevated SPAP and to identify patients evolving towards chronic pulmonary hypertension. Similarly, the preoperative radiographic assessment could help identify a subgroup of patients at higher risk of recurrence, directing them towards a more strict surgical followup.

The ipsilateral and contralateral areas were considered separately, evaluating the impact of hernia on each lung. We demonstrated that the ipsilateral area, which is more seriously affected by visceral herniation, has the most significant influence on patient outcomes.

Finally, focusing on FETO patients, we confirm the positive effects of the fetal procedure on lung catch-up growth and patient outcome.

Patients from our cohort showed a broad spectrum of disease severity, including infants requiring fetal surgery and ECMO support, and the standardization of treatment in accordance with international guidelines guarantee uniformity of care.

A certain technical difficulty in tracing the lungs' perimeter in severe forms must be underlined first among our study's limitations. We arbitrarily decided to consider only those parts of the radiograms where a lung plot was present, corresponding to those regions effectively recruited and ventilated. This methodological decision could constitute a bias leading to underestimating the lung dimensions since atelectasis areas had been excluded from the measurement.

Another significant limitation is related to the retrospective design of the study. The sample size was limited, and some missing data regarding SPAP estimation could not be integrated with further assessments, nor the number of patients could be incremented. We recognize that several factors could 
influence pulmonary vascular resistance and mortality throughout the hospital stay. The sample size should then be increased to allow a more unified subgroups analysis.

As research perspectives, serial assessments of the radiographic lung area during the hospital stay, remarkably the comparison between pre- and postoperative condition, could clarify the association between area, SPAP, and mortality, especially in most severe forms. We also aim to investigate the radiographic lung area's possible role in predicting the need for ECMO support through a prospective multicenter cohort study.

In conclusion, the radiographic pulmonary area on the first day of life reflects impaired lung development during fetal life and the extent of the diaphragmatic defect in $\mathrm{CDH}$ patients. Lower lung areas are associated with higher SPAP values at birth, death, and hernia recurrence. Further studies are needed to consolidate these results and define the radiographic lung area's possible role for $\mathrm{CDH}$ early risk assessment, monitoring, and outcome prediction.

\section{Methods}

The present study was carried out in accordance with the principles of good clinical practice and the Helsinki Declaration, as well as the national legislative and administrative provisions in force. This study was approved by the local Ethics Committee (Milan Area 2, Italy) with approval number OSMAMI04/05/2020-0015998-U, and due to the retrospective nature of the study the informed consent was waived by the Ethics Committee.

The study is part of a cohort study called NeoAPACHE (Assessment of the Pulmonary Area in Newborns with Congenital diaphragmatic HErnia), performed at NICU of Fondazione IRCCS Ca' Granda Ospedale Maggiore Policlinico, Milan, Italy, on CDH patients over a 6 years-period (January 2012 - December 2018). A comprehensive description of the study design has been previously published ${ }^{15}$.

As a primary objective, we aimed to evaluate the relationship between radiographic pulmonary area assessed on the first day of life and:

1. Pulmonary hypertension at birth, indirectly estimated by measuring the SPAP through tricuspid valve regurgitation gradient;

The secondary objectives were:

2. Death during the first year of life;

3. Recurrence of $\mathrm{CDH}$ among survivors at one year of life.

Moreover, the radiological features and outcomes of neonates submitted to FETO compared to those expectantly managed were analyzed and described. 


\section{Subjects}

As previously described, we enrolled all newborns having a preoperative chest X-ray performed within $24 \mathrm{~h}$ after birth at our NICU. Death within 1 hour, rotated, and air leak radiographs were excluded ${ }^{15}$. Surgery was performed as soon as the patient was clinically stable through median laparotomy with either primary repair or Gore-Tex ${ }^{\circledR}$ patch insertion ${ }^{33}$. After discharge, all patients were included in a multidisciplinary follow-up program $8,33,34$.

\section{Assessment of radiographic pulmonary area}

Each patient's pulmonary area was assessed by freehand tracing of the diaphragm and rib cage's perimeter, excluding the mediastinal structures and herniated organs ${ }^{15}$. If the anatomy was particularly disrupted, the only aerated portion of the lung was considered. The corresponding area was automatically calculated by the software Synapse PACS (FUJIFILM Medical Systems USA, Inc.). On each radiogram, three measurements were performed:

1. ipsilateral pulmonary area $\left(\mathrm{cm}^{2}\right)$;

2. contralateral pulmonary area $\left(\mathrm{cm}^{2}\right)$;

3. total pulmonary area $\left(\mathrm{cm}^{2}\right)$, obtained as the sum of the preceding two.

\section{Data collection}

Data regarding prenatal history, clinical, and surgical course were collected from each patient's medical records. Echocardiograms performed after birth (T0), pre-surgery (T1), post-surgery (T2), 7 days after surgery (T3) were reviewed, and reported SPAP values were recorded. CDH recurrence after surgical repair and the number of deaths in the first year of life were considered. Data acquisition was anonymous.

\section{Statistical analysis}

Continuous variables were reported as mean (standard deviation) or median (interquartile range); categorical variables were presented as number and percentage. For the comparison between groups, Student's T-Test, Mann-Whitney U Test, or Fisher Exact Test were applied as appropriate.

The radiographic assessment's reproducibility has already been demonstrated in the primary analysis, using the Bland Altman plot and calculating the Pearson Correlation index ${ }^{15}$.

Logistic regression models were used to evaluate the relationship between the lung area and death or hernia recurrence risk. Linear regression models were used to assess the effects of lung area on SPAP values. The models were corrected for gestational age at birth, as this variable could independently influence the patient's lung development and survival.

The ROC curve was also calculated to assess the radiographic measurement's discriminatory capacity, thus analyzing the test's sensitivity and specificity 
Statistical analysis was performed using IBM SPSS ${ }^{\circledR}$ Statistics V26.0. A p-value of 0.05 or lower was considered to be statistically significant.

\section{Ethical considerations}

The present study was carried out in accordance with the principles of good clinical practice and the Helsinki Declaration, as well as the national legislative and administrative provisions in force. This study was approved by the local Ethics Committee (Milan Area 2, Italy) with approval number OSMAMI04/05/2020-0015998-U.

\section{List Of Abbreviations}

$\mathrm{CDH}$ : congenital diaphragmatic hernia

PH: pulmonary hypertension

CRTA: chest radiographic thoracic area

FETO: fetal endoscopic tracheal occlusion

NICU: Neonatal Intensive Care Unit

O/E LHR\%: observed/expected lung to head ratio

sPAP: systolic pulmonary artery pressure

ROC: Receiver Operating Characteristic

ECMO: extracorporeal membrane oxygenation

AUC: area under the curve

\section{Declarations}

\section{Data availability}

The study was registered at ClinicalTrials.gov with identifier NCT04396028. Moreover, the datasets generated during and/or analyzed during the current study are available from the corresponding author.

\section{Acknowledgments}

The authors would like to thank all the Neonatal ECMO Team Mangiagalli of the Fondazione IRCCS Ca' Granda Ospedale Maggiore Policlinico: nurses and neonatologists of the NICU, surgeons of the Department of Pediatric Surgery, anesthesiologists of the Pediatric Anesthesiology and Intensive Care Unit, nurses of the operating room. 


\section{Author Contributions}

IA, GC, GR, SGa, SGh, VC, GB, NPes, and FMo contributed to the study's conception and design; IA, GR, GC, VC, SGa, SGh, and FMa wrote the first draft of the manuscript. IA, NPes, and GC calculated the sample size, IA and NPes performed the statistical analysis. IA and IB assessed radiographic pulmonary areas. IB, NPer, IF, FMa, AMC, MC, and FMo provided extensive critical revision. All authors contributed to manuscript critical revision, read and approved the submitted version.

\section{Funding}

None

\section{Competing Interests}

The authors declare that the research was conducted in the absence of any commercial or financial relationships that could be construed as a potential conflict of interest

\section{References}

1. Grover, T. R. et al. Short-Term Outcomes and Medical and Surgical Interventions in Infants with Congenital Diaphragmatic Hernia. Am. J. Perinatol.32, 1038-1044 (2015).

2. Deprest, J. et al. Prenatal management of the fetus with isolated congenital diaphragmatic hernia in the era of the TOTAL trial. Semin. Fetal Neonatal Med.19, 338-348 (2014).

3. Gleason, C. A. \& Devaskar, S. U. Avery's diseases of the newborn. (Elsevier Saunders, 2012).

4. Pierro, M. \& Thébaud, B. Understanding and treating pulmonary hypertension in congenital diaphragmatic hernia. Semin. Fetal Neonatal Med.19, 357-363 (2014).

5. Snoek, K. G. et al. Congenital Diaphragmatic Hernia: 10-Year Evaluation of Survival, Extracorporeal Membrane Oxygenation, and Foetoscopic Endotracheal Occlusion in Four High-Volume Centres. Neonatology113, 63-68 (2017).

6. Coughlin, M. A. et al. Prenatally diagnosed severe $\mathrm{CDH}$ : mortality and morbidity remain high. J. Pediatr. Surg.51, 1091-1095 (2016).

7. Bagolan, P. \& Morini, F. Long-term follow up of infants with congenital diaphragmatic hernia. Semin. Pediatr. Surg.16, 134-144 (2007).

8. American Academy of Pediatrics Section on Surgery \& American Academy of Pediatrics Committee on Fetus and Newborn. Postdischarge follow-up of infants with congenital diaphragmatic hernia. Pediatrics121, 627-32 (2008).

9. Rocha, G., Azevedo, I., Pinto, J. C. \& Guimarães, H. Follow-up of the survivors of congenital diaphragmatic hernia. Early Hum. Dev.88, 255-258 (2012).

10. Chen, C. et al. Long-term functional impact of congenital diaphragmatic hernia repair on children. J. Pediatr. Surg.42, 657-665 (2007). 
11. Dimitriou, G., Greenough, A., Kavvadia, V., Shute, M. \& Karani, J. A radiographic method for assessing lung area in neonates. Br. J. Radiol.72, 335-338 (1999).

12. May, C., Prendergast, M., Salman, S., Rafferty, G. F. \& Greenough, A. Chest radiograph thoracic areas and lung volumes in infants developing bronchopulmonary dysplasia. Pediatr. Pulmonol.44, 80-85 (2009).

13. Dassios, T., Curley, A., Krokidis, M., Morley, C. \& Ross-Russell, R. Correlation of radiographic thoracic area and oxygenation impairment in bronchopulmonary dysplasia. Respir. Physiol. Neurobiol.220, 40-45 (2016).

14. Dimitriou, G., Greenough, A., Davenport, M. \& Nicolaides, K. Prediction of outcome by computerassisted analysis of lung area on the chest radiograph of infants with congenital diaphragmatic hernia. J. Pediatr. Surg.35, 489-493 (2000).

15. Amodeo, I. et al. The NeoAPACHE Study Protocol I: Assessment of the Radiographic Pulmonary Area and Long-term Respiratory Function in Newborns with Congenital Diaphragmatic Hernia. Front. Pediatr. (2020) doi:10.3389/fped.2020.581809.

16. Dassios, T. et al. Prediction of Mortality in Newborn Infants With Severe Congenital Diaphragmatic Hernia Using the Chest Radiographic Thoracic Area. Pediatr. Crit. Care Med.20, 534-539 (2019).

17. Putnam, L. R. et al. Factors associated with early recurrence after congenital diaphragmatic hernia repair. J. Pediatr. Surg.52, 928-932 (2017).

18. Tsai, J., Sulkowski, J., Adzick, N. S., Hedrick, H. L. \& Flake, A. W. Patch repair for congenital diaphragmatic hernia: is it really a problem? J. Pediatr. Surg.47, 637-641 (2012).

19. Al-lede, M. M., Karpelowsky, J. \& Fitzgerald, D. A. Recurrent diaphragmatic hernia: Modifiable and non-modifiable risk factors. Pediatr. Pulmonol.51, 394-401 (2016).

20. Fisher, J. C., Haley, M. J., Ruiz-Elizalde, A., Stolar, C. J. H. \& Arkovitz, M. S. Multivariate model for predicting recurrence in congenital diaphragmatic hernia. J. Pediatr. Surg.44, 1173-1180 (2009).

21. Moss, R. L., Chen, C. M. \& Harrison, M. R. Prosthetic patch durability in congenital diaphragmatic hernia: A long-term follow-up study. J. Pediatr. Surg.36, 152-154 (2001).

22. Nagata, K. et al. Risk factors for the recurrence of the congenital diaphragmatic hernia-report from the long-term follow-up study of Japanese CDH study group. Eur. J. Pediatr. Surg.25, 9-14 (2015).

23. Leeuwen, L. \& Fitzgerald, D. A. Congenital diaphragmatic hernia. J. Paediatr. Child Health50,667673 (2014).

24. Kitagawa, M. Lung Hypoplasia in Congenital Diaphragmatic Hernia. 58, 342-346 (1971).

25. Dillon, P. W., Cilley, R. E., Mauger, D., Zachary, C. \& Meier, A. The relationship of pulmonary artery pressure and survival in congenital diaphragmatic hernia. J. Pediatr. Surg.39, 307-12; discussion 307-12 (2004).

26. Van der Veeken, L. et al. Fetoscopic endoluminal tracheal occlusion and reestablishment of fetal airways for congenital diaphragmatic hernia. Gynecol. Surg.15, (2018). 
27. Harting, M. T. Congenital diaphragmatic hernia-associated pulmonary hypertension. Semin. Pediatr. Surg.26, 147-153 (2017).

28. Rowe, D. H. \& Stolar, C. J. Recurrent diaphragmatic hernia. Semin. Pediatr. Surg.12, 107-109 (2003).

29. Jani, J. C. et al. Severe diaphragmatic hernia treated by fetal endoscopic tracheal occlusion. Ultrasound Obstet. Gynecol.34, 304-310 (2009).

30. Jani, J. et al. Observed to expected lung area to head circumference ratio in the prediction of survival in fetuses with isolated diaphragmatic hernia. Ultrasound Obstet. Gynecol.30, 67-71 (2007).

31. Doné, E. et al. Predictors of neonatal morbidity in fetuses with severe isolated congenital diaphragmatic hernia undergoing fetoscopic tracheal occlusion. Ultrasound Obstet. Gynecol.42, 7783 (2013).

32. Jawaid, W. B., Qasem, E., Jones, M. O., Shaw, N. J. \& Losty, P. D. Outcomes following prosthetic patch repair in newborns with congenital diaphragmatic hernia. Br. J. Surg.100, 1833-1837 (2013).

33. Snoek, K. G. et al. Standardized postnatal management of infants with congenital diaphragmatic hernia in Europe: the CDH EURO Consortium Consensus - 2015 Update. Neonatology110, 66-74 (2016).

34. Hollinger, L. E. \& Buchmiller, T. L. Long term follow-up in congenital diaphragmatic hernia. Semin. Perinatol.44, 151171 (2020).

\section{Figures}




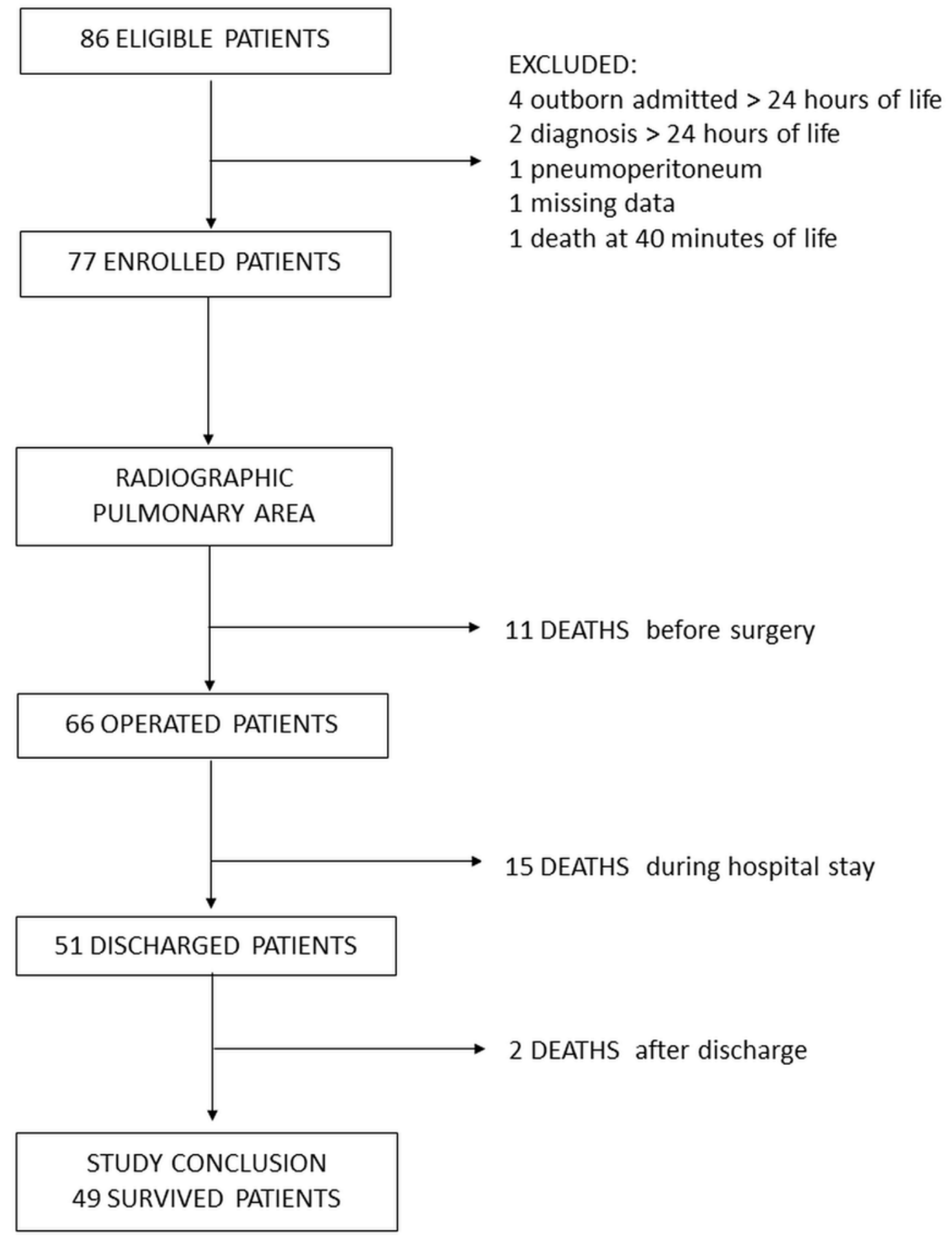

Figure 1

Study flowchart. 

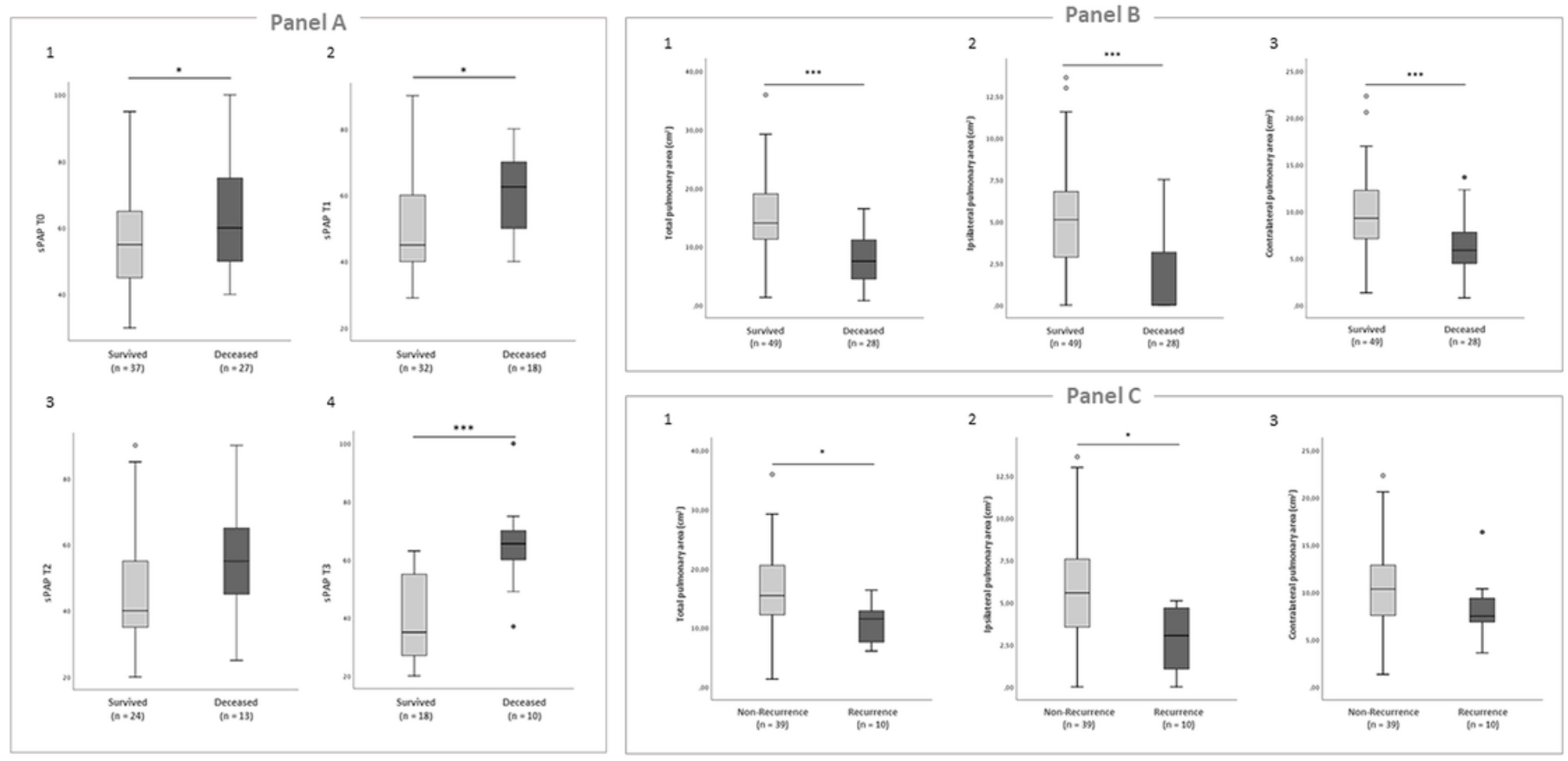

\section{Figure 2}

Panel A: boxplots showing the comparison of sPAP values between survived and deceased patients. Student's T-Test was performed to compare the two groups. 1: SPAP T0, $p=0.016 ; 2$ : $\operatorname{SPAP} T 1, p=0.022$; 3: $\operatorname{sPAP} T 2, p=0.163 ; 4$ : sPAP T3, $p<0.001$. Panel $B$ : boxplots showing the comparison of radiographic lung area on the first day of life between survived and deceased patients. Student's T-Test was performed to compare the two groups. 1 : total pulmonary area, $p<0.001 ; 2$ : ipsilateral pulmonary area, $p<0.001 ; 3$ : contralateral pulmonary area, $p<0.001$. Panel $\mathrm{C}$ : Boxplots showing the comparison of radiographic lung area on the first day of life between non-recurrence and recurrence patients. Student's T-Test was performed to compare the two groups. 1 : total pulmonary area, $p=0.034 ; 2$ : ipsilateral pulmonary area, $p$ $=0.011 ; 3$ : contralateral pulmonary area, $p=0.164$. 

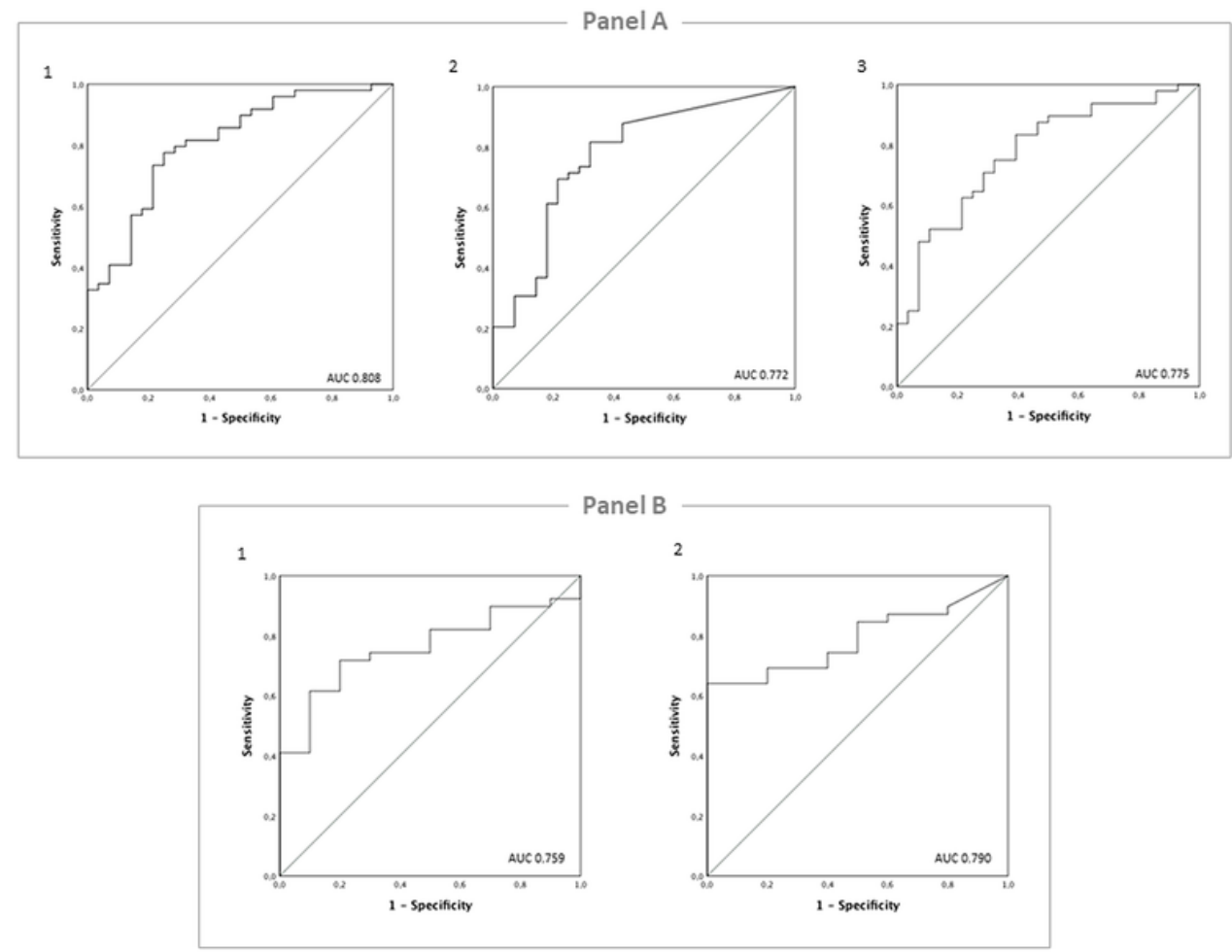

\section{Figure 3}

Panel A: ROC analysis and estimation of the corresponding area under the curve (AUC) for the radiographic pulmonary area's performance predicting survival to one year of life. 1: total pulmonary area; 2: ipsilateral pulmonary area; 3: contralateral pulmonary area. Panel B: ROC analysis and estimation of the corresponding area under the curve (AUC) for the radiographic pulmonary area's performance predicting hernia recurrence in the first year of life. 1: total pulmonary area; 2 : ipsilateral pulmonary area. 